\title{
Creep rupture behavior of welded Grade 91 steel
}

Triratna Shrestha ${ }^{1}$, Mehdi Basirat ${ }^{2}$, Sultan Alsagabi ${ }^{1}$, Anumat Sittiho ${ }^{1}$, Indrajit Charit ${ }^{\mathrm{a}, 1}$, Gabriel P. Potirniche ${ }^{2}$

${ }^{1}$ Department of Chemical and Materials Engineering, University of Idaho, Moscow, ID 83844, USA

${ }^{2}$ Department of Mechanical Engineering, University of Idaho, Moscow, ID 83844, USA

\begin{abstract}
Creep rupture behavior of fusion welded Grade 91 steel was studied in the temperature range of $600-700{ }^{\circ} \mathrm{C}$ and at stresses of $50-200 \mathrm{MPa}$. The creep data were analyzed in terms of the Monkman-Grant relation and Larson-Miller parameter. The creep damage tolerance factor was used to identify the origin of creep damage. The creep damage was identified as the void growth in combination with microstructural degradation. The fracture surface morphology of the ruptured specimens was studied by scanning electron microscopy to further elucidate the rupture mechanisms.
\end{abstract}

Keywords: Grade 91 steel; ferritic-martensitic steel; welding; creep rupture; fractography

\footnotetext{
${ }^{a}$ Corresponding author. I. Charit

E-mail: icharit@uidaho.edu; Tel.: +1-208-885-6964; Fax: +1-208-885-7462 


\section{Introduction}

The Next Generation Nuclear Plant (NGNP) are being developed and adopted to address ever-growing energy demand and reduce $\mathrm{CO}_{2}$ emissions. Various reactor types, such as Gas-Cooled Fast Reactor (GFR), Lead-Cooled Fast Reactor (LFR), Molten Salt Reactor (MSR), Sodium-Cooled Fast Reactor (SFR), Supercritical WaterCooled Reactor (SCWR), and Very High Temperature Reactor (VHTR) are being considered. The VHTR is a Gen-IV reactor system at the heart of the so-called Next Generation Nuclear Plant (NGNP). The VHTRs are expected to have a 60 plus years of service life and operate at higher temperature and pressure [1]. Depending on the VHTR design, Prismatic Modular Reactor (PMR) or Pebble Bed Modular Reactor (PBMR), the operating temperature of the reactor pressure vessel (RPV) can vary between $300{ }^{\circ} \mathrm{C}$ and $650^{\circ} \mathrm{C}$. Furthermore, the RPV in the VHTR will be more than twice the size of a typical RPV in a Light Water Reactor (LWR) [2]. The RPV is considered an irreplaceable component of a nuclear power plant, which dictates its useful service life. The modified 9Cr-1Mo (Grade 91) steel is being considered for the VHTR pressure vessel material. On the other hand, the Grade 91 steel has been a material of choice in fossil-fired power plants with increased efficiency and service life, and reduction in the greenhouse gas emissions of $\mathrm{CO}_{2}, \mathrm{NO}_{x}, \mathrm{SO}_{2}$, etc. The efficiency of a fossil-fired power plant depends on the temperature and pressure of the steam. The steam in these advanced coal-fired power plants is expected to have temperatures in the range of 550

- $720{ }^{\circ} \mathrm{C}$ and pressures above $24 \mathrm{MPa}$ [3-5]. The Grade 91 steel has better erosion/corrosion resistance than traditional steels in fluidized bed combustion (FBC) boiler waterwalls and superheater tubes. 
Understanding creep rupture properties of the Grade 91 steel is important for predicting the long term mechanical integrity of a power plant. Furthermore, welding is an essential manufacturing step for large power plant components. Although there are some studies on the creep-rupture properties of monolithic Grade 91 steel [6, 7], there is only a limited number of studies on the creep rupture properties of the welded Grade 91 steel. Monolithic Grade 91 steel exhibited two different rate-controlling creep deformation mechanisms in the lower stress region and in the higher stress region [8]. The creep deformation mechanism in the low stress region was identified as the Nabarro-Herring creep with stress exponent of $\sim 1$, while that in high stress region was identified as high temperature dislocation climb with stress exponent of $\sim 5$ [8]. A diagnostic diagram for creep failure of monolithic Grade 91 steel showed that microstructural degradation phenomena such as particle coarsening, subgrain growth and cavity nucleation/growth played a major role in creep-rupture [6, 8-12]. The fracture mechanism map of Grade 91 steel developed by Shrestha et al. [6] indicated that the monolithic samples ruptured via transgranular mode.

Welding of Grade 91 steel creates microstructural gradient across the weldment. This inhomogeneity in microstructure, mainly in the heat affected zone (HAZ), leads to type-IV cracking $[13,14]$ and low creep strength in the fine grain HAZ (FGHAZ) [15-19]. The exact location of type-IV cracking, whether in over-tempered martensite, FGHAZ, or inter-critical HAZ (ICHAZ), is still not settled. Partial transformation of austenite to martensite, resulting in presence of retained austenite [20], formation of delta-ferrite [2125], and differential migration of interstitial and precipitate forming elements [26, 27] across the weldment creates a complex microstructure prone to failure. 
The focus of this work was to analyze the creep rupture data obtained from a fusion welded Grade 91 steel and compare them with the data obtained by author's previous work on monolithic Grade 91 steel and with data available in literature on welded Grade 91 . The previous studies by some of the current authors were focused on tensile creep properties of monolithic Grade 91 steel. Creep rupture behavior of the steel was studied and a failure mechanism map was developed [6]. In a separate study [8], creep deformation of the steel was studied in high stress and low stress regime whereas creep deformation of the steel was modeled using continuum-damage technique [28]. Furthermore, the study correlates the creep rupture data in the light of both phenomenological and physical understanding. Specifically, an attempt has been made to analyze the data in terms of creep fracture diagnostic approach that has not been done by any contemporary work on this important steel under welded condition.

\section{Experimental details}

\subsection{Material and welding procedure}

The chemical composition of ASTM A387 Grade 91 CL2 steel (Grade 91) used in this study is given in Table 1. The hot rolled Grade 91 plates were obtained from ArcelorMittal Plate LLC, in a normalized and tempered condition (i.e., austenitized at $1038{ }^{\circ} \mathrm{C}$ for $240 \mathrm{~min}$ followed by air cooling and tempered at $788^{\circ} \mathrm{C}$ for $43 \mathrm{~min}$ ). The asreceived plates had dimensions of $104 \mathrm{~mm} \times 104 \mathrm{~mm} \times 12.7 \mathrm{~mm}$. The plates of aforementioned dimensions were cut into two halves and tapered on one side at $30^{\circ}$ to make a V-butt end. Using tungsten gas arc welding (GTAW), double V-butt weld specimens were made by welding these two V-butt end halves together, as shown in Fig. 1, where Long represents the longitudinal direction, Trans represents the 
transverse direction, and TT the through-thickness direction. A Metrode $2.4 \mathrm{~mm}$ diameter 9CrMoV-N TIG filler wire having low residual elements was used for welding. The plates were pre-heated to $260{ }^{\circ} \mathrm{C}$ before welding. The steel plates were placed on an aluminum plate to prevent overheating during welding. Three successive passes were used to create the complete weld using a current of $130 \mathrm{~A}$ and a voltage of $15 \mathrm{~V}$. Post-weld heat treatment (PWHT) of the welded plates were carried out at $750{ }^{\circ} \mathrm{C}$ for 2 hr. The creep rupture tests were performed on PWHTed samples.

\begin{tabular}{ccc}
\multicolumn{3}{c}{ Table 1. Chemical composition (in wt.\%) of Grade 91 steel } \\
\hline Element & Nominal & Measured \\
\hline $\mathbf{C r}$ & $8.00-9.50$ & 8.55 \\
$\mathbf{M o}$ & $0.85-1.05$ & 0.88 \\
$\mathbf{~ V ~}$ & $0.18-0.25$ & 0.21 \\
$\mathbf{~ N b}$ & $0.06-0.10$ & 0.08 \\
$\mathbf{C}$ & $0.08-0.12$ & 0.10 \\
$\mathbf{M n}$ & $0.30-0.60$ & 0.51 \\
$\mathbf{C u}$ & 0.4 (max.) & 0.18 \\
$\mathbf{S i}$ & $0.20-0.50$ & 0.32 \\
$\mathbf{N}$ & $0.03-0.07$ & 0.035 \\
$\mathbf{N i}$ & 0.40 (max.) & 0.15 \\
$\mathbf{P}$ & 0.02 (max.) & 0.012 \\
$\mathbf{S}$ & 0.01 (max.) & 0.005 \\
$\mathbf{T i}$ & 0.01 (max.) & 0.002 \\
$\mathbf{A l}$ & 0.02 (max.) & 0.007 \\
$\mathbf{Z r}$ & 0.01 (max.) & 0.001 \\
$\mathbf{F e}$ & Balance & Balance \\
\hline
\end{tabular}
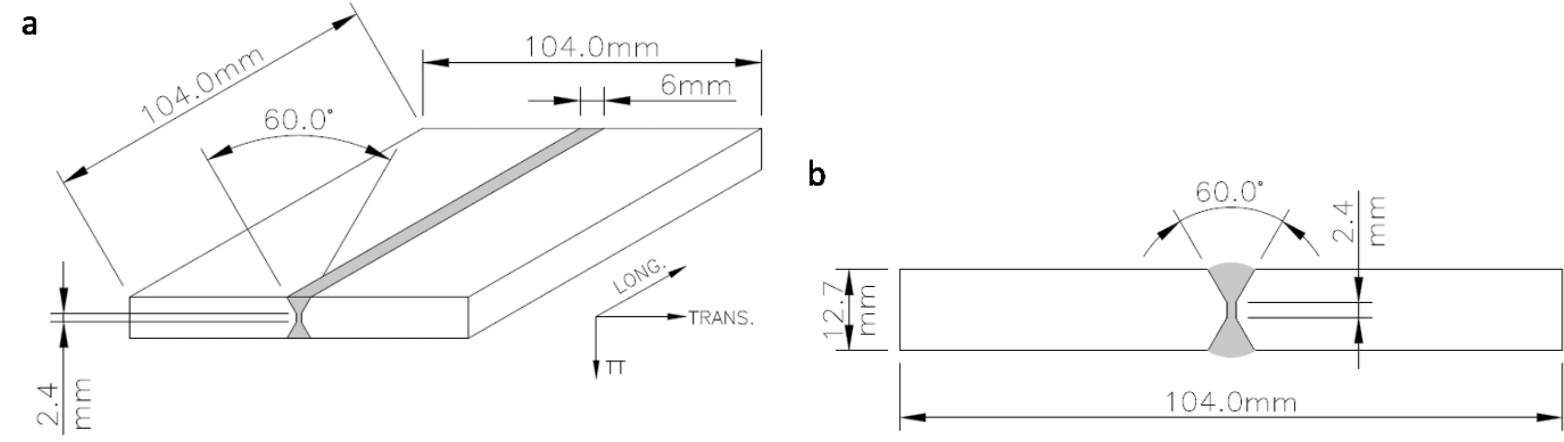

Fig. 1. Schematic representation of the double V-butt welded plate.

\subsection{Microstructural characterization}


Optical microscopy was performed on the as-received, welded, and creep tested specimens for characterization of the grain structure. Conventional metallographic procedures of cold mounting, grinding, and polishing were followed to prepare the specimen surface to $0.5 \mu \mathrm{m}$ finish before etching was carried out using Marble's reagent, a solution made of $50 \mathrm{ml}$ distilled water, $50 \mathrm{ml}$ hydrochloric acid, and $10 \mathrm{~g}$ of copper sulfate. Subsequently, an Olympus light microscope was used to examine the metallographic specimens and an attached CCD camera was used to record the micrographs.

For detailed microstructural characterization, some metallographic samples were examined using a Zeiss Supra 35VP field emission gun scanning electron microscope (FEG-SEM) operated at an accelerating voltage of $10-20 \mathrm{kV}$ in secondary electron imaging mode. Relevant chemical compositional analyses were performed by energy dispersive spectroscopy (EDS) technique available in the FEG-SEM. Further, transmission electron microscopy (TEM) was performed on some specific creep-tested specimens. In this regard, a JEOL 2010J STEM was utilized at an accelerating voltage of $200 \mathrm{kV}$. The TEM sample preparation was carried out with a Fischione twin-jet electropolisher using an electrolytic solution of methanol and nitric acid (nominal volume ratio of $85: 15$ ) in a dry ice bath (about $-35^{\circ} \mathrm{C}$ ).

Microhardness testing was carried out using a Vickers microhardness tester (LECO LM-100) where the applied load was $500 \mathrm{~g}_{\mathrm{f}}(4.9 \mathrm{~N})$ and the hold time $15 \mathrm{~s}$.

\subsection{Creep testing}


Creep tests were performed in air under tension at different temperatures $\left(600{ }^{\circ} \mathrm{C}\right.$ to $700{ }^{\circ} \mathrm{C}$ ) and stresses between 50 and $200 \mathrm{MPa}$ using an Applied Test Systems (ATS) lever arm (20:1) creep tester (model 2335). Creep strain was measured using an ATS 4124 averaging extensometer. The test temperatures were selected so as to study the high temperature creep-resistance of the steel as it is seen as a prospective material for reactor pressure vessel in nuclear reactors that would experience high temperatures and as heat exchanger tubes in ultra super critical power plants in which temperatures can be as high as $720{ }^{\circ} \mathrm{C}$. Cylindrical, dog-bone shaped tensile creep specimens with a gage length of $2.54 \mathrm{~cm}$ and diameter of $0.64 \mathrm{~cm}$ was used for the testing. Though creep tests were intended for fracture, some tests in the lower stress regime were interrupted within the steady creep stage in order to avoid prolonged testing time. More details about creep testing can be found elsewhere [8].

\section{Results and Discussion}

\subsection{Microstructural characteristics of as-received and as-welded materials}

The as-received Grade 91 steel consisted of a tempered martensitic microstructure as shown in Fig. 2a. Precipitation hardening is one of the main strengthening mechanisms in highly alloyed steels like Grade 91. Alloying elements, such as $\mathrm{C}, \mathrm{N}, \mathrm{Ti}, \mathrm{Nb}, \mathrm{V}, \mathrm{Cr}$ and Mo, promote the formation of precipitates like Cr-rich $\mathrm{M}_{23} \mathrm{C}_{6}$, and $\mathrm{Nb}$ - or $\mathrm{V}$-rich $\mathrm{MX}$ particles, where $\mathrm{M}$ stands for metals, i.e., $\mathrm{Cr}, \mathrm{Mo}, \mathrm{Ti}, \mathrm{Nb}$ or $\mathrm{V}$, and $\mathrm{X}$ stands for $\mathrm{C}$ or $\mathrm{N}$. Based on the temperature experienced by the weldment, the microstructure would vary across the weldment resulting in a microstructural gradient. The coarse $\mathrm{M}_{23} \mathrm{C}_{6}$ precipitates are stable at lower temperature, while the fine MX type precipitates are stable at higher temperature [29]. The Cr-rich $\mathrm{M}_{23} \mathrm{C}_{6}$ 
precipitates are elongated rod-like or block-like particles, while Nb-rich and V-rich MX precipitates have near-spherical shapes $[6,8]$. These thermally stable fine precipitates generally help in enhancing the long term creep resistance of the alloy. A SEM micrograph in Fig. $2 b$ shows the distribution of precipitates along the grain boundaries and inside the grains. The coarser $\mathrm{M}_{23} \mathrm{C}_{6}$ type precipitates were located on the grain boundaries, lath boundaries, and prior austenite grain boundaries, while finer MX type precipitates were mainly located inside the grains. Microstructural features of the welded and PWHTed specimens: the unaffected base material (BM), HAZ, and weld zone (WZ) are shown in Fig. 3. Two distinct HAZ microstructures, i.e. coarse and fine grain structures, and an indistinctive columnar structure formed after directional solidification were observed in the weld. The representative microstructures of the BM, FGHAZ, CGHAZ, and WZ are shown in Figs. 3a, b, c, and d, respectively.
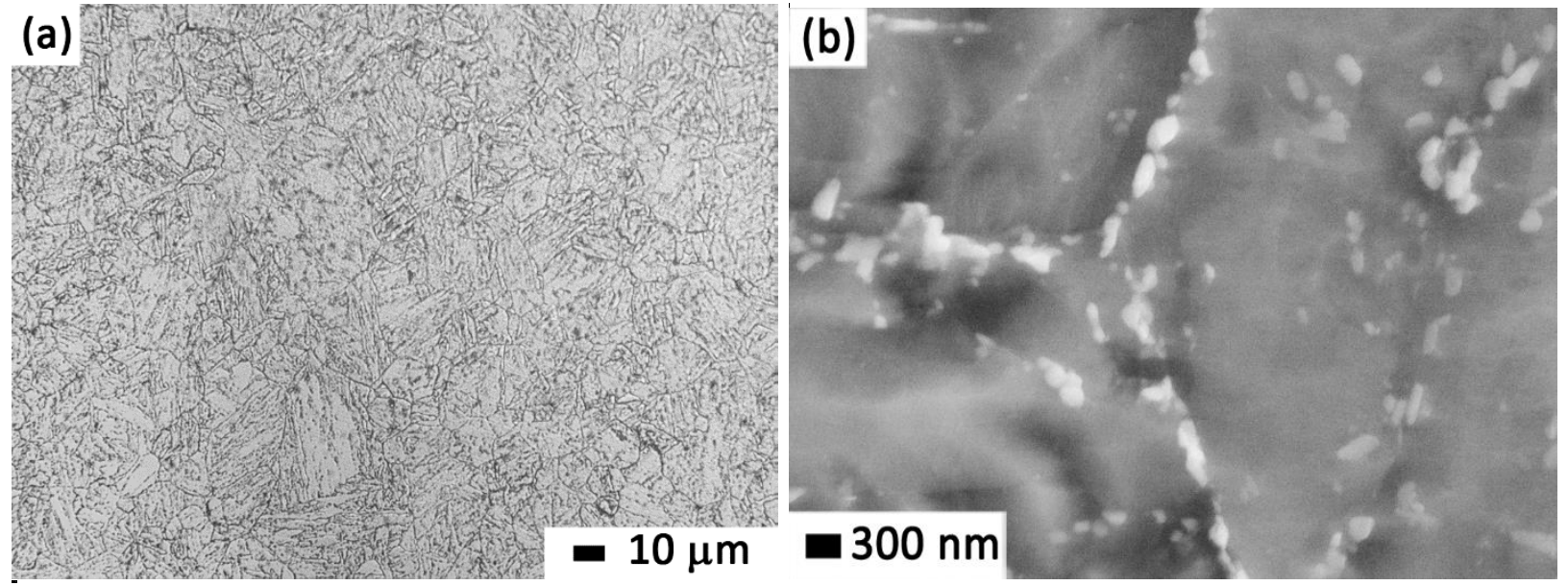

Fig. 2. Microstructure of as-received Grade 91 steel: (a) an optical micrograph showing the tempered martensitic structure and (b) a SEM micrograph showing the distribution of precipitates. 

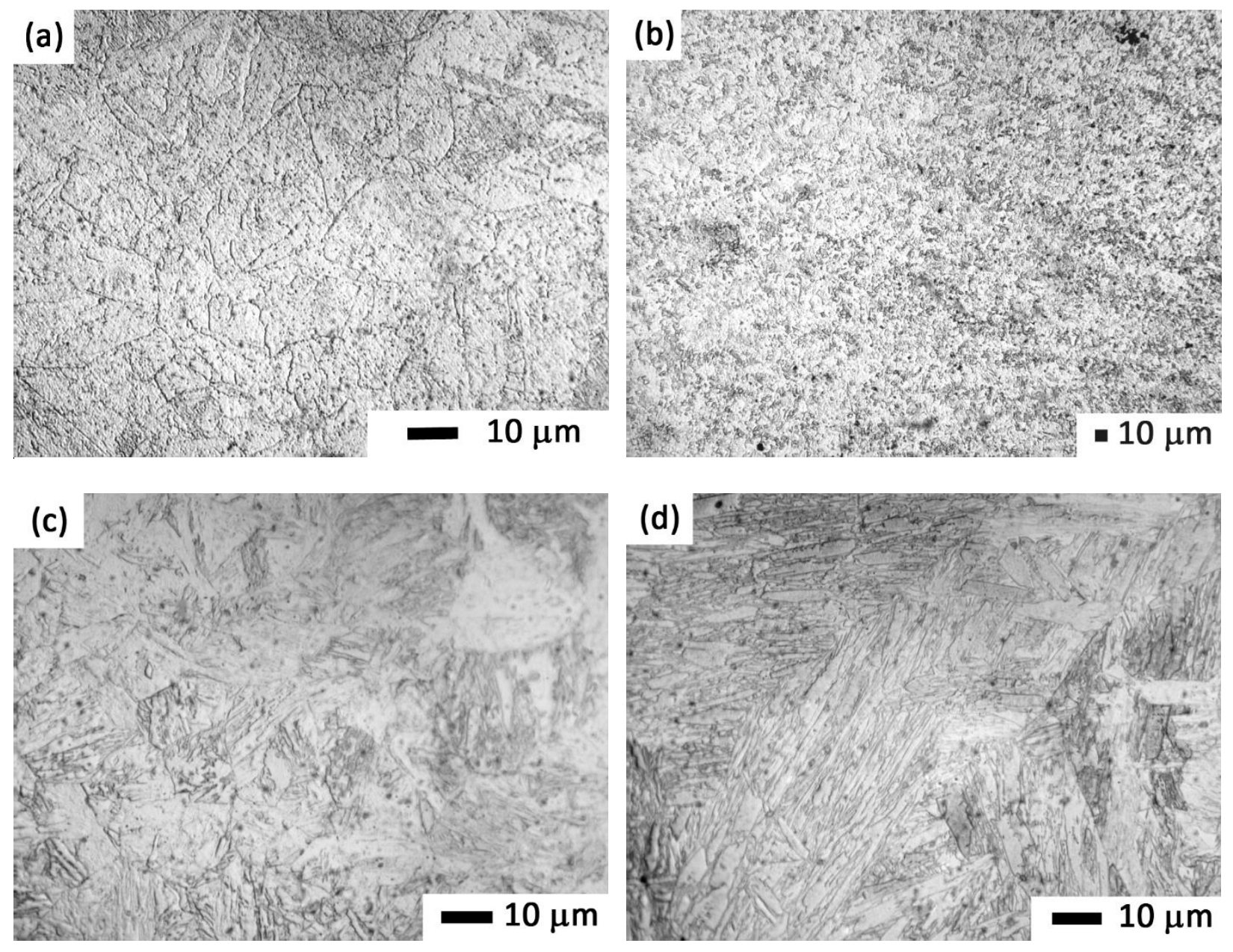

Fig. 3. Optical micrographs of the weldment section: (a) base material, (b) fine grain HAZ, (c) coarse grain HAZ, and (d) weld zone.

\subsection{Microstructural and microhardness characteristics of PWHTed specimen}

The test specimen consisted of a complex microstructure: BM, HAZ and WZ, as shown in Figure 4a. The thermal history of the weldment and associated microstructural evolution introduces detrimental residual stresses across the weldment, which reduces the creep life of the material by early onset of creep damage [30-32]. The presence of tensile residual stress in $\mathrm{HAZ}$, as a result of welding, accelerates the carbide coarsening, which enhances the formation of voids [13,33-34] leading to the creation of a soft zone. Hardness, a measure of resistance to plastic deformation, can also provide information on the microstructural degradation. Vickers microhardness testing was 
performed across the cross section of an as-welded and PWHTed Grade 91 steel, as shown in Fig. 4b. The PWHTed samples were used for creep testing. The PWHT was able to significantly reduce the microhardness across the weldment, as shown in Fig. 4b. The hardness of the weldment increased across the weld but decreased at HAZ as compared to the base metal. The decrease in hardness at HAZ is due to the dissolution and coarsening of strength-enhancing carbides [6]. Moreover, as the material starts to cool down after welding, the FCC crystal structure of the austenite phase undergoes a diffusionless transformation to a BCT crystal structure, with an accompanying volume increase $[35,36]$. This change in volume is associated with changing of the residual stress pattern from tensile to compressive [37]. Thus, the increase in hardness values at the weld is related to the martensitic transformation which leads to compressive residual stresses in the weld. The decrease in microhardness at the HAZ reflects the presence of an over-tempered martensite along with the $\delta$-ferrite phase, dislocation-free and precipitate-free microstructure [29]. The ferrite and austenite phases are more prone to plastic deformation compared to the martensitic phase [38]. Welding leads to the migration of carbon, creating soft areas in the HAZ, which are the likely initiation sites of type-IV cracking. In the current study, the lowest hardness was measured in the HAZ because of the reduction in dislocation density, coarsening of precipitates, formation of polygonized structure, and break-up of martensitic lath structure as shown in Fig. 4c and other studies $[39,40]$. Coarsened $\mathrm{M}_{23} \mathrm{C}_{6}$ particles present in the $\mathrm{HAZ}$ are denoted by arrows in Fig. 4c. In the same image, poorly delineated subgranular sub-structure is also evident. In line with the current study, a similar type of hardness profile was reported by Sato et al. [41] across the weld joint of a modified $9 \mathrm{Cr}-1 \mathrm{Mo}$ steel. The 
decrease in hardness reflects the diminished yield strength at the HAZ, which results in premature failure of the weldment [13]. The HAZ considered as the soft zone in the weldment with a low yield strength undergoes plastic deformation more concentrated within it than the other zones.
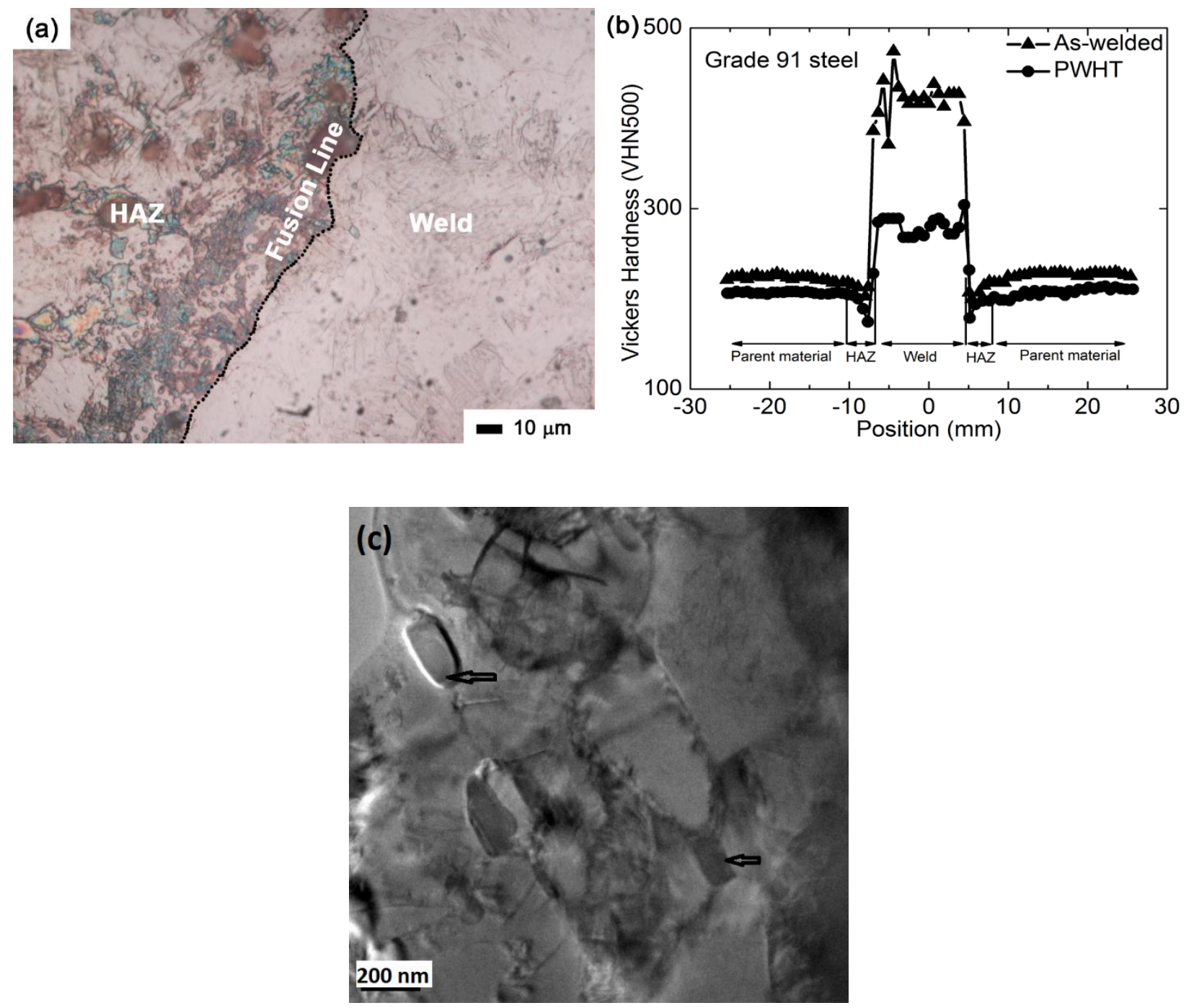

Fig. 4. (a) An optical microscopy image of a weldment showing microstructural degradation in HAZ, (b) microhardness profile of an as-welded and PWHTed sample, and (c) A TEM image from the HAZ region of the PWHTed Grade 91 with coarsened $\mathrm{M}_{23} \mathrm{C}_{6}$ particles.

\subsection{Creep properties}


During the primary creep, the creep rate decreased with increasing strain due to work hardening via dislocation multiplication and interactions. In the secondary stage, the creep rate is stabilized as the work hardening effect is counterbalanced by dislocation annihilation and rearrangement [8]. Finally, the creep rate accelerates as the damage mechanisms start to dominate, leading to the tertiary stage and eventual failure. Most creep curves obtained in this study consisted of two distinct regions: primary and tertiary, and a minimum creep rate region between the two regions. Fig. $5 a$ compares the creep rate of a welded Grade 91 steel with a monolithic Grade 91 steel at $650{ }^{\circ} \mathrm{C}$ and $150 \mathrm{MPa}$. The welded samples had significantly lower rupture lives and higher creep rates. Fig. 5b shows the effect of applied stress on the creep rate of the welded specimens at a temperature of $600{ }^{\circ} \mathrm{C}$. The minimum creep rates increased and the rupture time decreased with increasing applied stress. Fig. $5 c$ shows the effect of test temperature on creep rates at an applied stress of $100 \mathrm{MPa}$. Quite similar to the effect of applied stress, the minimum creep rate increased and the rupture time decreased with increasing temperature. Table 2 lists the creep rupture data of welded specimens.
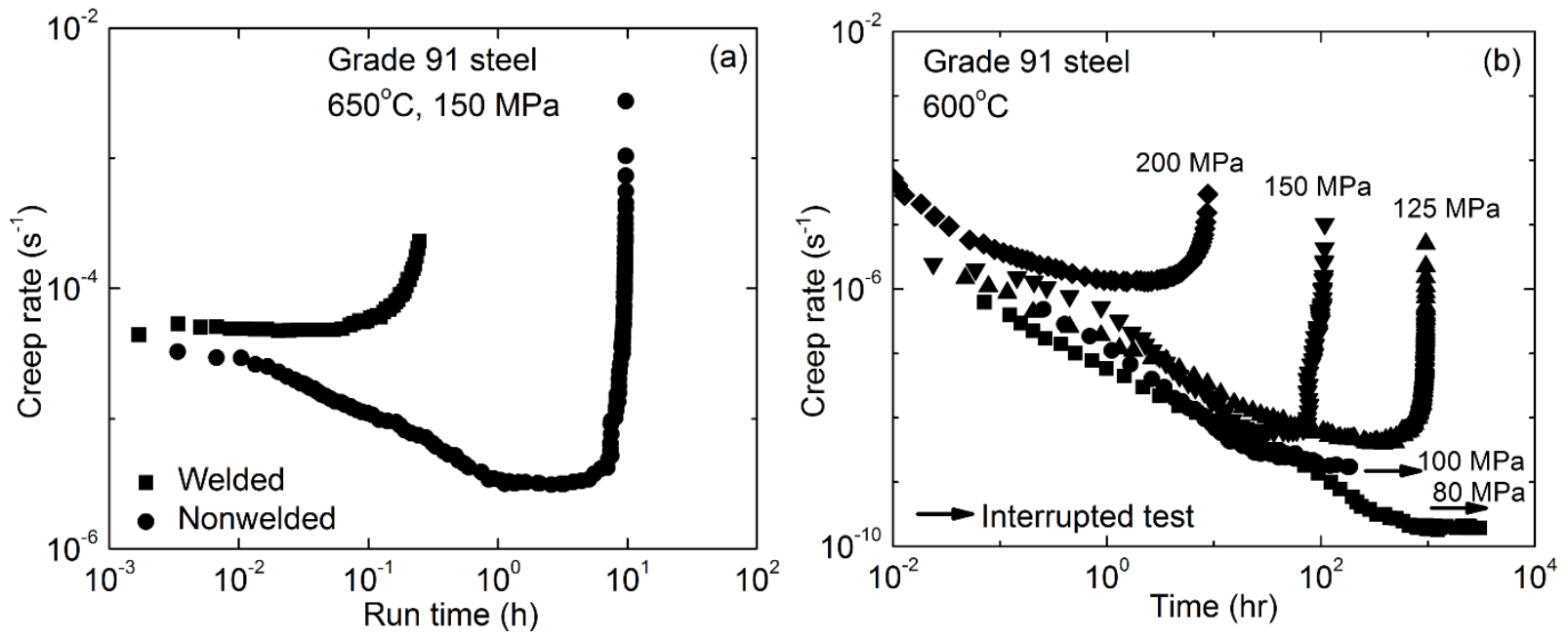


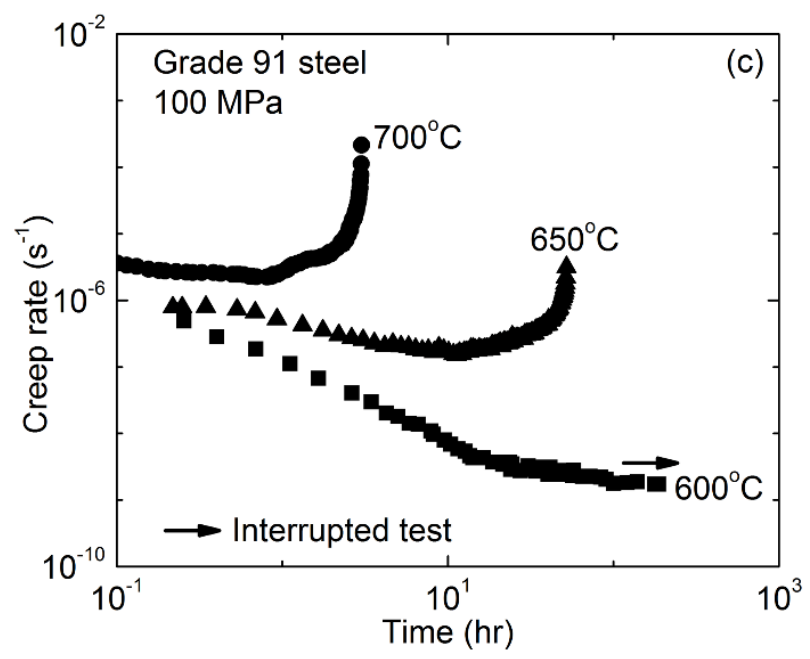

Fig. 5. (a) Variation of strain rates for both welded and monolithic (i.e., unwelded) samples at $600{ }^{\circ} \mathrm{C}$ and an applied stress of $150 \mathrm{MPa}$, (b) variation of strain rates as a function of stress in welded samples at $600{ }^{\circ} \mathrm{C}$, and (c) the variation of strain rates with temperature in welded samples at $100 \mathrm{MPa}$.

Table 2. Summary of creep rupture data of the welded samples

\begin{tabular}{ccccc|}
\hline Temp. $\left({ }^{\circ} \mathbf{C}\right)$ & $\begin{array}{c}\text { Stress } \\
(\mathbf{M P a})\end{array}$ & $\begin{array}{c}\text { Fracture } \\
\text { Elongation }(\%)\end{array}$ & $\begin{array}{c}\text { Reduction in Area } \\
(\%)\end{array}$ & $\begin{array}{c}\text { True Fracture } \\
\text { Strain }\left(\boldsymbol{\varepsilon}_{\boldsymbol{f}}\right)\end{array}$ \\
\hline 600 & 125 & 6 & 43 & 0.6 \\
600 & 150 & 8 & 74 & 1.4 \\
600 & 200 & 11 & 85 & 1.9 \\
650 & 50 & 4 & 40 & 0.5 \\
650 & 80 & 6 & 48 & 0.7 \\
650 & 100 & 8 & 58 & 0.9 \\
650 & 125 & 9 & 73 & 1.3 \\
650 & 150 & 10 & 91 & 2.4 \\
700 & 50 & 7 & 52 & 0.7 \\
700 & 80 & 8 & 62 & 0.9 \\
700 & 100 & 10 & 80 & 1.6 \\
700 & 150 & 10 & 93 & 2.8 \\
700 & 200 & 14 & 92 & 2.5
\end{tabular}

The total creep rupture life is related to the duration of primary and secondary creep stage by the following relationship [7]

$\frac{t_{R}^{\gamma}}{t_{t s}}=C$ 
where $t_{t s}$ is the time to reach tertiary creep stage, $t_{R}$ the rupture time, $C$ and $\gamma$ are constants. When $t_{t s}$ data were plotted against $t_{R}$ data in a double logarithmic scale for both the welded and monolithic samples, all the data fall on a single straight line whose slope is the value of constant $\gamma(\sim 1.1)$, as shown in Fig. $6 \mathrm{a}$. It is noted that the relation between the rupture time and the time to reach tertiary creep stage is independent of temperature, microstructure, and deformation mechanism. The creep rupture data of the monolithic samples from the edge dislocation climb controlled regime and welded samples for various temperatures are presented in the stress versus rupture time in Fig. 6b. Clearly, the monolithic samples appear to have better creep strength compared to the welded ones. For the creep test performed at $700{ }^{\circ} \mathrm{C}$ and $100 \mathrm{MPa}$, the rupture time of monolithic and welded samples were $10 \mathrm{~h}$ and $3 \mathrm{~h}$, respectively. For the creep test performed at $650{ }^{\circ} \mathrm{C}$ and $100 \mathrm{MPa}$, the rupture times of monolithic and welded samples were $568 \mathrm{~h}$ and $52 \mathrm{~h}$, respectively. Due to time constraint, all $600{ }^{\circ} \mathrm{C}$ tests performed below $125 \mathrm{MPa}$ were interrupted. As shown in Fig. 6(b), no change in the slope was noted at any particular temperature for the monolithic and welded samples implying that the creep damage mechanism remained the same under the test conditions. Nevertheless, the knowledge of such microstructural instability is important as they could lead to significant errors in the extrapolation of the data to longer time [42]. 

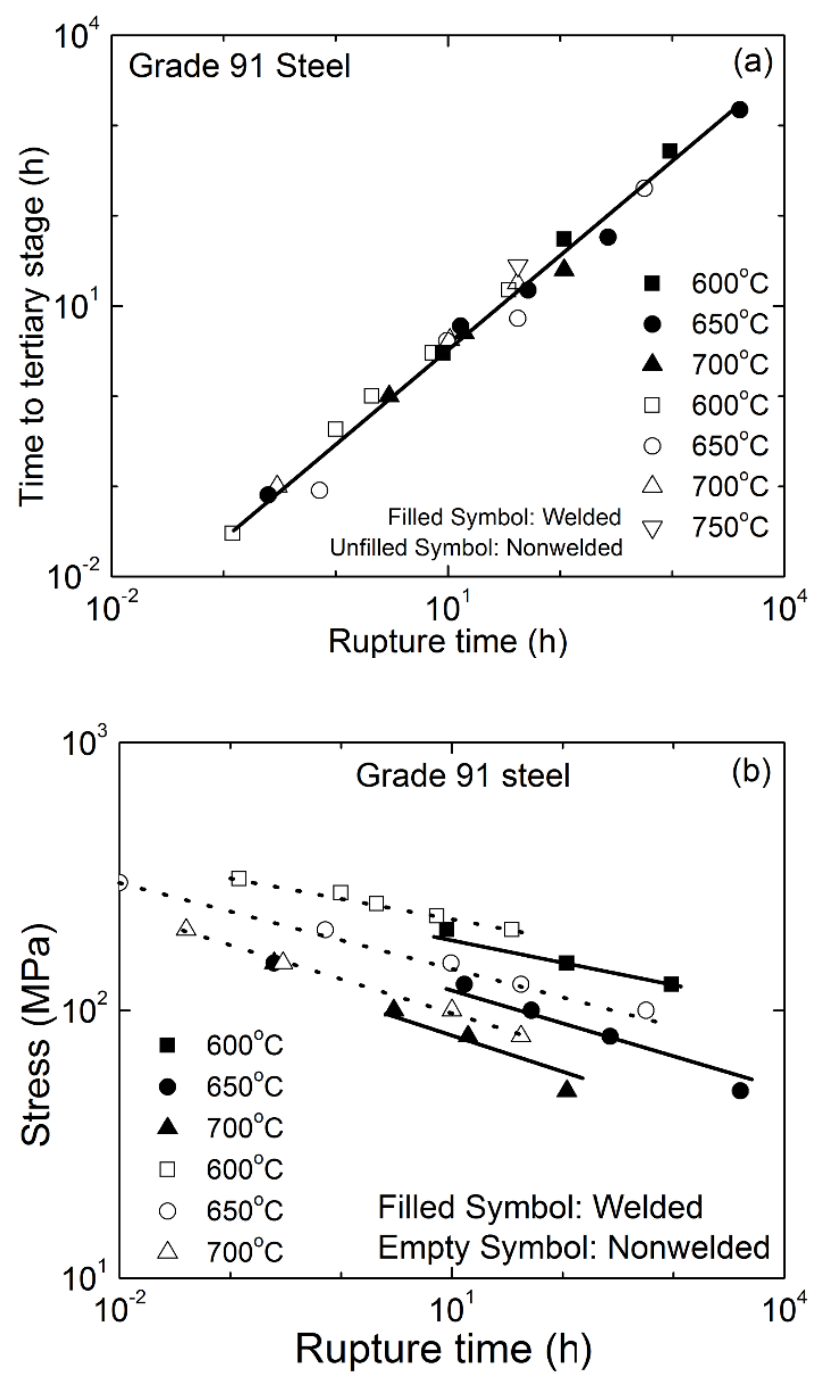

Fig. 6. (a) Relation between the creep rupture life and the time to reach the tertiary creep stage and (b) stress and temperature dependence of creep rupture life.

\subsection{SEM Fractography and TEM Examination}

The welded creep specimens ruptured with limited external necking and reduction in area compared to monolithic ones. The reduction in area $(\geq 40 \%)$ of a welded sample was not as significant as in monolithic samples, which had a reduction in area of $\geq 85 \%$. For a particular temperature, the percentage reduction in area decreased with decrease in applied stress. Similarly, the true fracture strain of the welded samples were in the range of $0.7-2$. This is distinctly different compared to the 
monolithic samples, which had true fracture strain of $\geq 2$ in all stress regimes [6]. Heterogeneous microstructure, pre-existing residual stresses across the weldment, and limited reduction in the load-bearing cross-section could contribute to the cause creep rupture. The significance of internal necking through microstructural degradation, cavity formation, growth and coalescence must be taken into account to understand the final failure mechanisms. Laha et al. [13] and Albert et al. [16, 17] have reported increase in cavity density in HAZ. Furthermore, creep cavities and cracks start forming inside of a sample [43], and the cavity density was higher at the mid-thickness of the HAZ compared to the outer or inner surface [17]. It is important to note that welded samples did not fail by complete necking implying that the internal damage processes had a significant bearing on the failure mode. Generally, cavities form throughout the creep deformation; however, in the tertiary stage nucleation and growth of cavities take place at an accelerated pace. Moreover, the grain size gradient, and the presence of dislocation and precipitate-free microstructure in the weldment makes it easier for cavities to form in the welded samples.

The SEM study of fracture surfaces of the crept specimens revealed dominant dimple features, as shown in Figures $7 a$ and b. These features are consistent with transgranular mode of fracture. Similar fracture morphology was also reported by Laha et al. [13] in welded Grade 91 steel. Fig. 7a and b shows the SEM micrograph of dimpled fracture surface in specimens crept at $700{ }^{\circ} \mathrm{C} / 200 \mathrm{MPa}$ and $600{ }^{\circ} \mathrm{C} / 125 \mathrm{MPa}$, respectively. Fig. 7c shows a transgranular crack in FGHAZ of a specimen crept at 700 ${ }^{\circ} \mathrm{C} / 80 \mathrm{MPa}$. The sample crept at $700{ }^{\circ} \mathrm{C} / 200 \mathrm{MPa}$ had the transgranular fracture mode, but the number density of cavities was lower while the average size were larger than the 
sample crept at $600{ }^{\circ} \mathrm{C} / 125 \mathrm{MPa}$. For creep-enhanced diffusive cavity growth, increasing stress leads to greater cavity growth rates and coalescence resulting in a smaller number density. It can be noted that the sample crept at $600{ }^{\circ} \mathrm{C} / 125 \mathrm{MPa}$ had a reduction in area of about $43 \%$ and a true fracture strain of about 0.6 , while the sample crept at $700{ }^{\circ} \mathrm{C} / 200 \mathrm{MPa}$ had a reduction in area of about $92 \%$ and a true fracture strain of about 2.5. The creep specimens mainly failed in transgranular mode. The creep cavities observed were found to be round or elliptical in shape (r-type crack). The growth of incipient $r$-type cracks is controlled by diffusion, but as the cavity size increases, they grow following the power law creep, and in transition they grow as a coupled effect of the diffusion creep and power law creep [44]. While precipitates increase the creep strength of materials by impeding the dislocation motion, they act as stress concentration sites for cavity nucleation during creep deformation. Creep damage is due to the combined effect of cavity nucleation, growth and coalescence, as shown in Figure $7(\mathrm{~d})$. In the sample crept at $600{ }^{\circ} \mathrm{C} / 125 \mathrm{MPa}$, a SEM image of the cross-section shows a larger cavity created due to the interlinkage or coalescence of several cavities. Figs. 7c and d show that even though the two specimens were deformed at two different temperatures, very similar morphology of cavities were observed. The cavities act as a stress raiser where the localized stress exceeds the applied stress resulting in plastic deformation. Eventually, excessive plastic strain at the particle-matrix interface leads to decohesion. That effect can be further exacerbated by grain boundary sliding if the particle is located at the grain boundary [45]. 


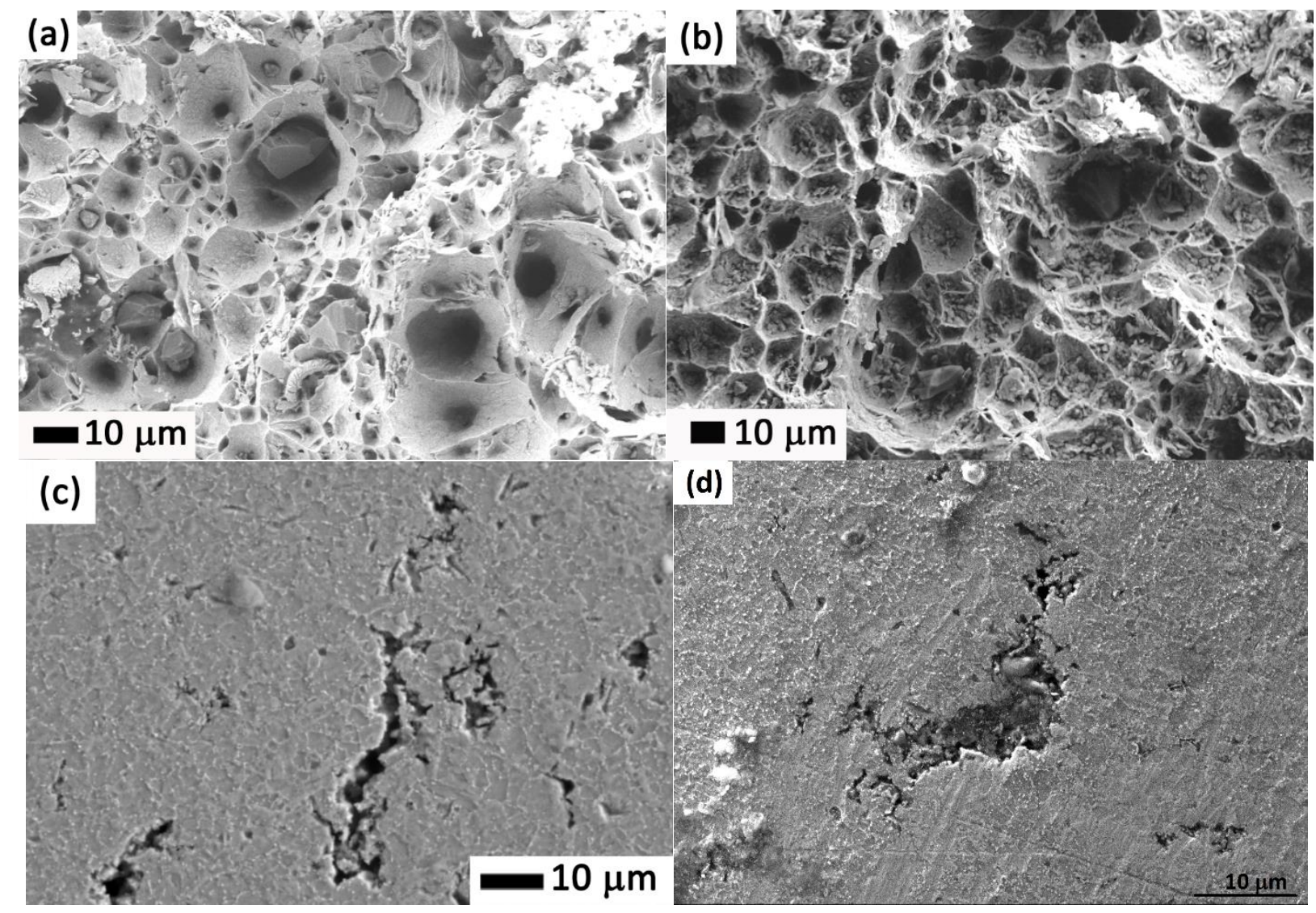

Fig. 7. SEM-SE micrographs of the fractured samples: (a) dimpled fracture surface in a specimen crept at $700{ }^{\circ} \mathrm{C} / 200 \mathrm{MPa}$, (b) dimpled fracture surface in a specimen crept at 600 ${ }^{\circ} \mathrm{C} / 125 \mathrm{MPa}$, (c) transgranular crack in FGHAZ of a specimen tested at $700{ }^{\circ} \mathrm{C} / 80 \mathrm{MPa}$, and (d) cavity coalescence and growth in FGHAZ of a specimen crept at $600^{\circ} \mathrm{C} / 125 \mathrm{MPa}$.

Fig. 8a shows a SEM micrograph of cavities present in the fracture tip of a sample crept at $600{ }^{\circ} \mathrm{C} / 125 \mathrm{MPa}$. The necked area next to the fractured surface had higher density of cavity, while the cross section away from the fracture surface had limited cavitation. The extent of cavitation depends on the amount of local strain. Fig. 8b shows the variation of Vickers microhardness of sample crept at $600{ }^{\circ} \mathrm{C} / 125 \mathrm{MPa}$. The fracture point is indicated as ' 0 ' which had the lowest hardness of $56 \mathrm{VHN}$. Aside from the fracture point, the HAZ on the right had the lowest hardness of $186 \mathrm{VHN}$, while the weld had the highest hardness of $270 \mathrm{VHN}$. This hardness profile is similar to the one discussed in Section 3.2 and is shown in Figure 4b. A creep specimen has two HAZ 
regions on either side of a weld. The hardness profile inversely correlates with the true local strain. The fracture point and the HAZ on right had the highest true localized strains, but lowest hardness. Remarkably, the weld section of the specimen had negligible true local strain. Thus, all the deformation was localized at the HAZ. The HAZ, where the creep damage was concentrated and had high true strain, undergoes true tertiary stage, while other parts on the gauge section showing little true strain had not reached the tertiary creep stage. However, the tertiary creep at the HAZ section was so dominant compared to other regions of the weld that it was responsible for the final failure of the specimen.
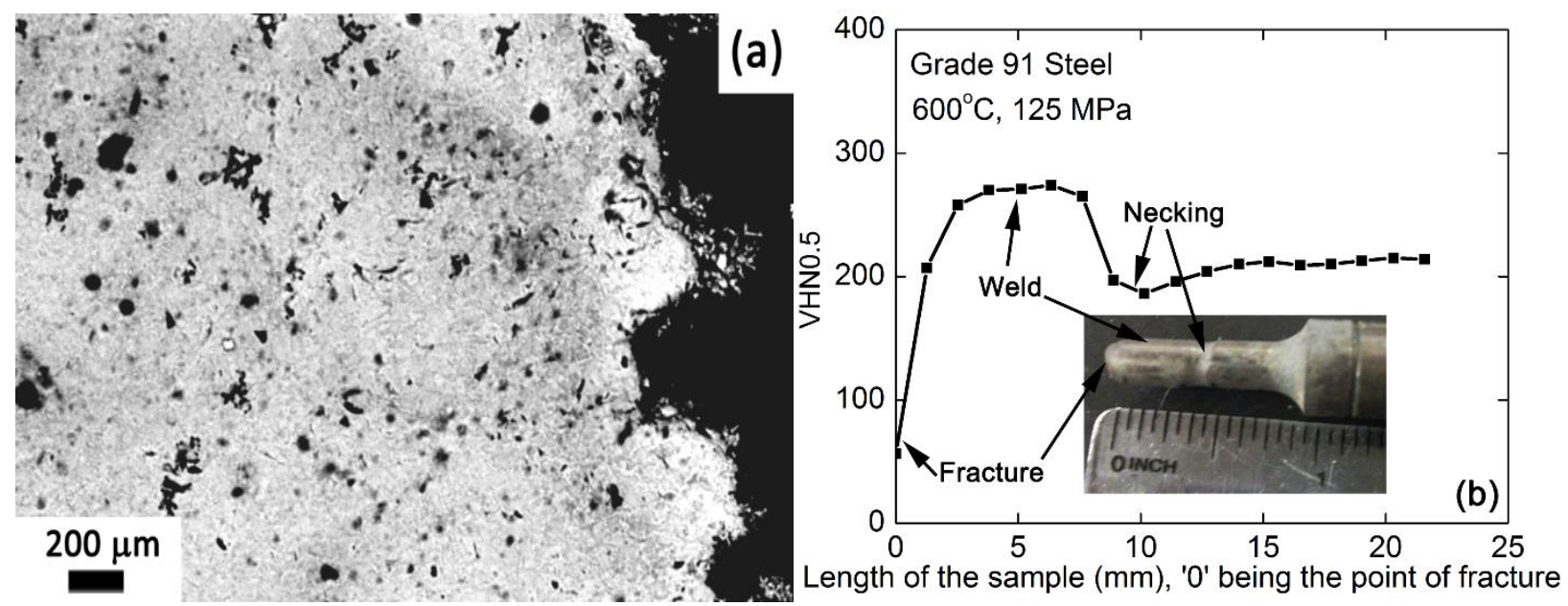

Fig. 8. (a) A SEM micrograph showing damage present at the fracture tip, the sample was crept at $600{ }^{\circ} \mathrm{C}$ and $125 \mathrm{MPa}$; and (b) the variation of microhardness with position in specimens fractured at $600{ }^{\circ} \mathrm{C}$ and $125 \mathrm{MPa}$.

Some TEM work was performed on two crept specimens: one interrupted crept specimen $\left(600^{\circ} \mathrm{C} / 80 \mathrm{MPa}\right)$ and another ruptured crept specimen $\left(600^{\circ} \mathrm{C} / 200 \mathrm{MPa}\right)$. Creep data from both the specimens in terms of creep rate versus time have already been reported in Fig. 5b. The focus during the TEM study was kept on the surrounding regions of HAZ that are prone to eventual rupture. Figs. 9a and b show lower and 
higher magnification TEM images, respectively, of the crept specimen tested at $600{ }^{\circ} \mathrm{C}$ and $200 \mathrm{MPa}$. The images did not reveal any remnant of lath structure. Rather they indicate development of subgrain structure. Also, a SEM-SE fractographic image of the ruptured specimen tip is included in Fig. 9c. The morphological characteristics of the fractographic image is quite comparable to the fracture surface examined previously with dimple features. Figs. 10a and b show the TEM images of the specimen creep tested at $600{ }^{\circ} \mathrm{C}$ and $80 \mathrm{MPa}$, but the test was interrupted. The sample shows some remnants of lath-like structure; however, here also subgrain structure development was found to be clearly at work. It appears that the amount of stress does play an important role in destroying the lath structure.
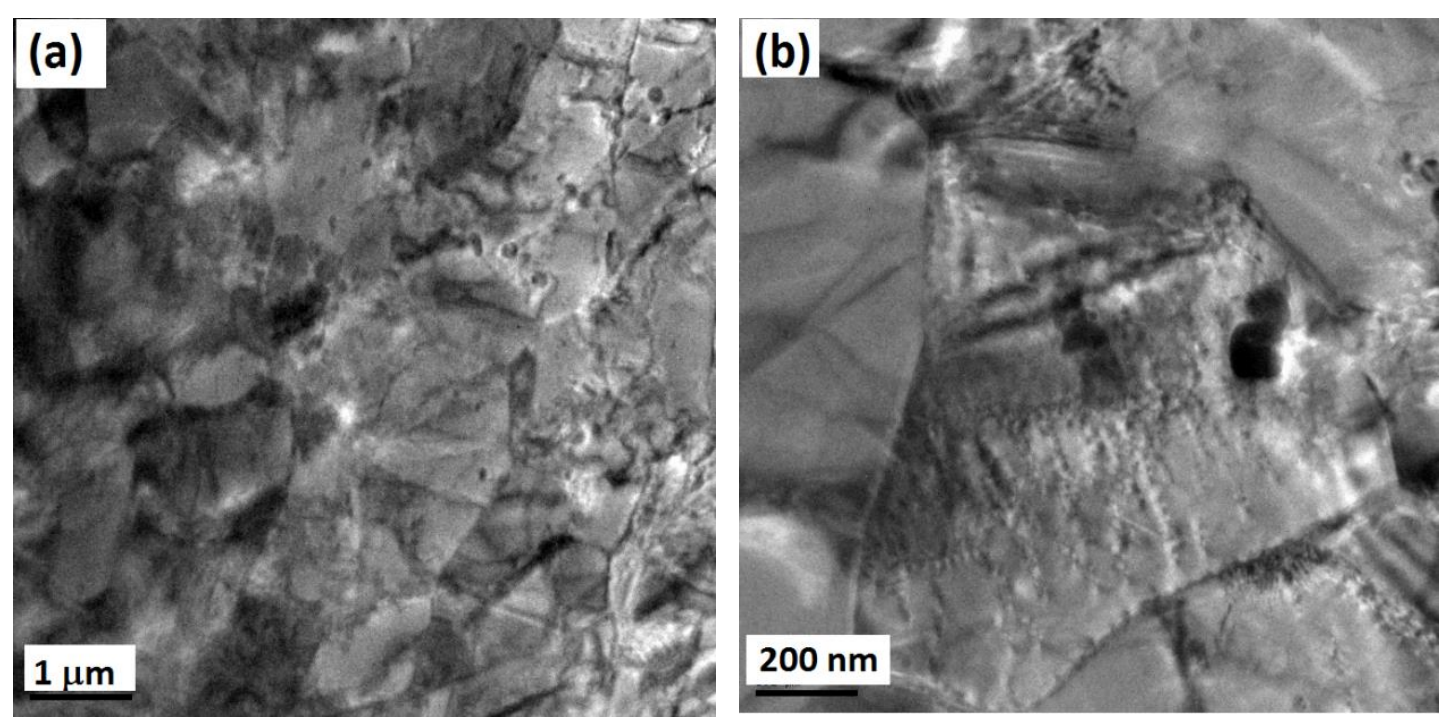


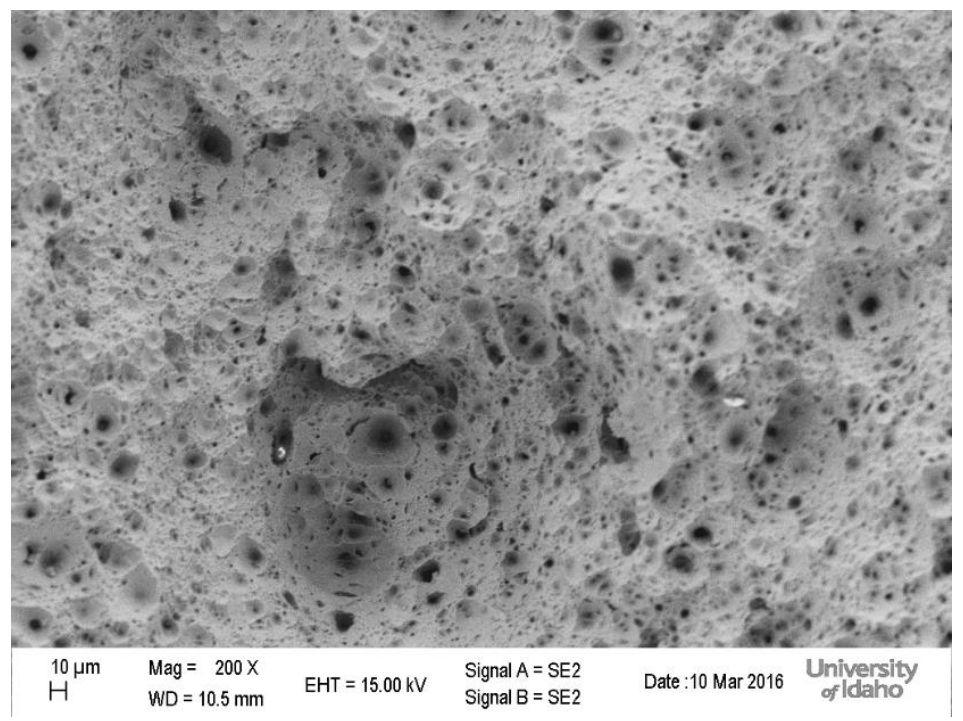

Figure 9. TEM images of the crept specimen $\left(600{ }^{\circ} \mathrm{C} / 200 \mathrm{MPa}\right)$ - specimen taken near from the fracture tip: (a) A low magnification image showing the overall microstructure. (b) A high magnification image showing the presence of subgrain structure. (c) A SEM-SE image showing the fracture surface of the same crept specimen.
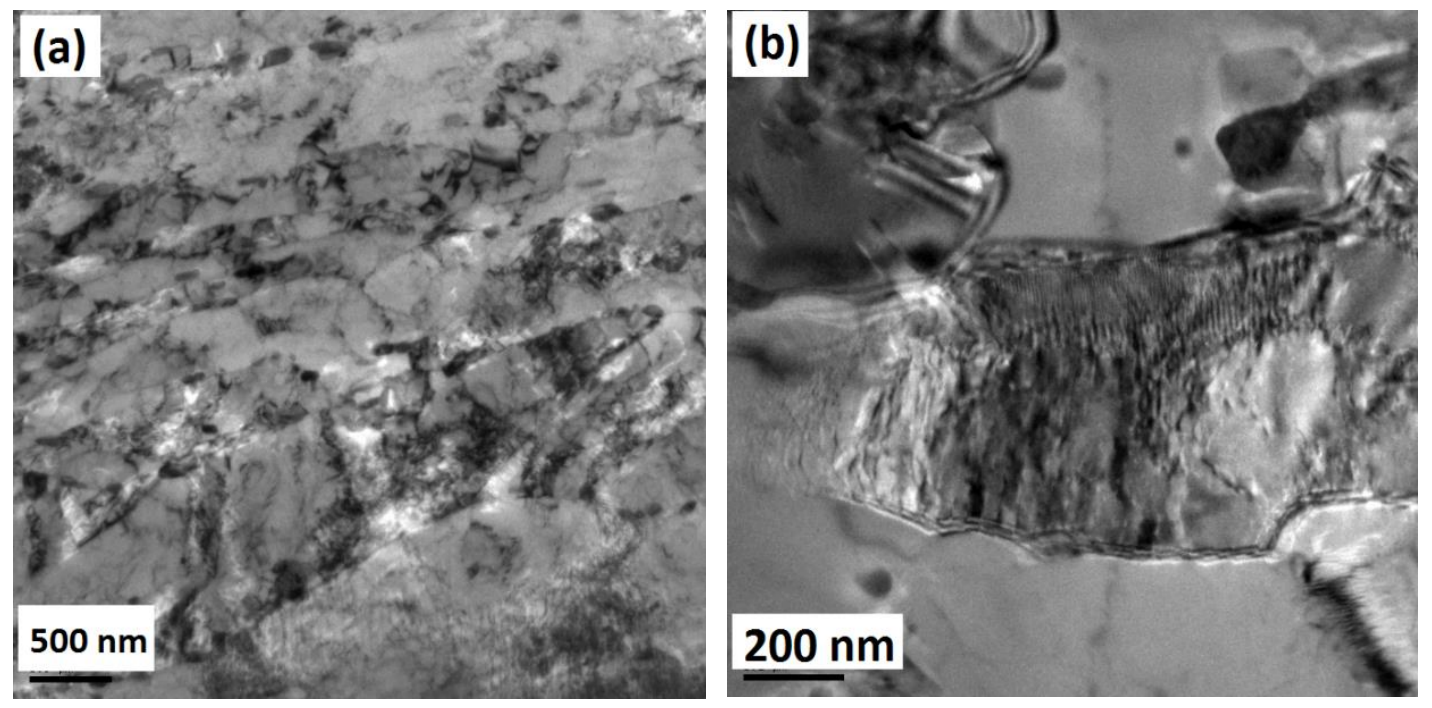

Figure 10. TEM images of the crept specimen $\left(600^{\circ} \mathrm{C} / 80 \mathrm{MPa}\right)$ - interrupted deformation (from the HAZ region): (a) A low magnification image showing the remnant of lath structure; (b) $A$ higher magnification image showing the development of subgrain structure.

\subsection{Creep rupture data analyses}

The relationship between the minimum creep rate and rupture life is given by the Monkman-Grant equation [46], 
$\dot{\varepsilon}_{m}^{m} t_{R}=K_{1}$,

where $\dot{\varepsilon}_{m}$ is the minimum creep rate, $t_{R}$ the rupture time, $m$ and $K_{1}$ are constants. The value of $K_{1}=0.04$ was obtained from the fitted straight line of the logarithmic relation deduced from Equation 2. Nabarro [47] noted that for a better prediction of creep rupture life, $m$ needs to be less than 1 . In this study, the $m$ was calculated to be 0.83 . Thus, using the above relationship the creep rupture life can be predicted based on the experimentally determined minimum creep rate.

Monkman and Grant [46], and Evans [48] found that the value of $K_{1}$ was 0.04 for monolithic ferritic steel and 0.08 for monolithic austenitic steel, and predicted that the $K_{1}$ to be less than inverse of stress exponent $(n)$. The stress exponents $(n)$ of welded creep specimens were $\sim 7$, as shown in Fig. 11 , which is common in engineering alloys like Grade 91 steel. The stress exponent of 7 indicated that the rate-controlling deformation mechanism is likely to the recovery-based dislocation climb mechanism. The substructure development as noted in crept specimens (Figs. 9 and 10) can also attributed to the operation this kind of creep deformation mechanism. A similar creep deformation mechanism was reported in tungsten inert gas (TIG) welded P92 steel, which is also a ferritic-martensitic (F-M) grade of steel [49]. The inverse of the calculated stress exponent $(n)$ was $\sim 0.14$. The fit in Fig. 12 a resulted in $K_{1}$ to be 0.04 , quite similar to the value obtained for monolithic samples [6]. For a material to fail by complete necking, $K_{1}$ has to be equal to $n^{-1}[48]$. Thus, necking is not the dominant fracture mode in the creep-rupture of welded samples. 


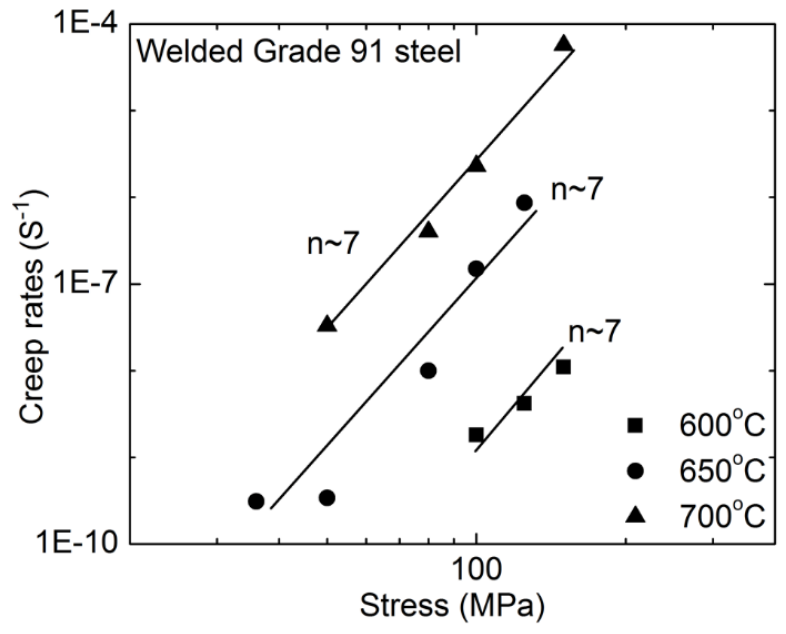

Fig. 11. Strain rate vs. stress plot of the welded Grade 91 steel
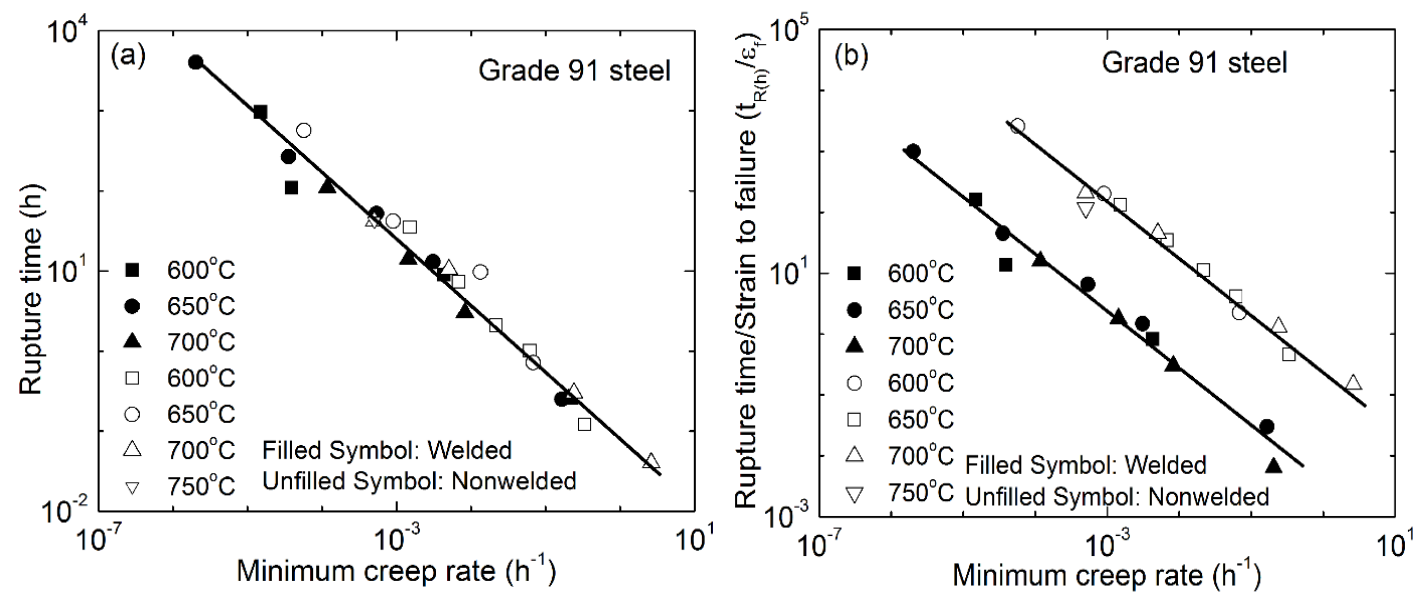

Fig. 12. (a) Monkman-Grant relation and (b) modified Monkman-Grant relation.

With regards to engineering alloys like Grade 91 steel, Dobes et al. [50] modified the aforementioned Monkman-Grant relation to obtain a better correlation of the rupture time with the minimum creep rate following the equation,

$\dot{\varepsilon}_{m} m^{\prime} \frac{t_{R}}{\varepsilon_{f}}=K_{2}$,

where $\varepsilon_{f}$ is the strain at fracture (based on elongation to fracture), $K_{2}$ and $m^{\prime}$ are constants. The modified equation is able to differentiate between the welded and monolithic samples, as shown in Figure 12b, which is in contrast to Figure 12a. The 
value of $K_{2}$ was found to be 0.45 from fitting of the logarithmic plot deduced from Equation 3, as shown in Fig. 12b. Eq. (3) was used to calculate the creep damage tolerance factor (CDTF) or $\lambda$ for identifying creep rupture mode. For $m^{\prime}=1, \lambda$ is given by inverse of $K_{2}$ [51, 52]. The CDTF values for engineering alloys range from 1 to 20 [52].

For $\lambda=1$, materials have low creep strain and brittle fracture mode is detected as they fracture without any significant plastic deformation, while large values indicate that the material can withstand strain concentration without localized cracking and the fracture is ductile $[47,52]$. In their classical treatment of creep rupture phenomenon, Ashby and Dyson [52] suggested that $\lambda$ in the range of 1.5 and 2.5 indicates that damage is due to the cavity growth resulting from the combined effect of power law creep and diffusion creep. Incipient cavities grow by diffusion, but power law creep takes over as they become larger [44]. High $\lambda$ value was attributed to the absence of intergranular cracks, absence of wedge shaped cracks, and to the microstructural degradation like precipitate coarsening. Dominant creep damage mechanism is necking for $\lambda$ higher than 2.5 [52], while coarsening of precipitates and subgrains, and decrease in dislocation density are the dominant creep damage mechanism when $\lambda$ is 5 or higher $[52,53]$. $A$ creep damage tolerance $\lambda$ of 1.5 was observed in a MA957 alloy, an yttrium bearing oxide dispersion strengthened (ODS) ferritic alloy, which fractured with little evidence of neck formation [54]. In this study, creep damage tolerance factor of $\sim 2.2$ was obtained. The $\lambda$ value of $\sim 2.2$ indicates that the creep damage is due to cavity growth resulting from combined effect of the power law and diffusion creep, necking and microstructural degradation. Coarsening of precipitates and subgrains in Grade 91 steel can decrease the creep strength as they become less effective in disrupting the 
movement of mobile dislocations $[9-12,8,28]$. However, in the present study the creep rupture tests carried out were of relatively shorter duration unlike long-term creep testing and no significant particle coarsening was observed in the microstructure of the crept specimens. However, theses microstructures as shown in TEM images of Figs. 9 and 10 did exhibit unique substructural development. Thus, the microstructural degradation process during the tertiary stage is associated with the characteristic cellular/subgranular networks formed, which allow for rapid recovery and accelerating of creep rates.

Monolithic Grade 91 steel had CDTF of $\sim 4$, and the dominant failure mechanism was identified as microstructural degradation with limited contribution from necking and void (or cavity) growth [6]. The welded Grade 91 steel had CDTF of $\sim 2.2$, meaning that the dominant failure mechanism is void growth with microstructural degradation without significant necking. This is illustrated in the diagnostic diagram for creep failure as shown in Fig. 13. The figure shows that all the creep rupture data reported in this study fell on the microstructural degradation and void growth domain with lower fracture strain. Moreover, the creep rupture data of the welded Grade 91 steel were compared with that of the monolithic alloy. The dominant creep fracture mechanism in precipitation strengthened monolithic Grade 91 steel was microstructural degradation with a limited contribution from void growth, while the welded Grade 91 steel with a complex microstructure (as shown in HAZ) exhibits void growth compounded by microstructural degradation - primarily in the HAZ region. 


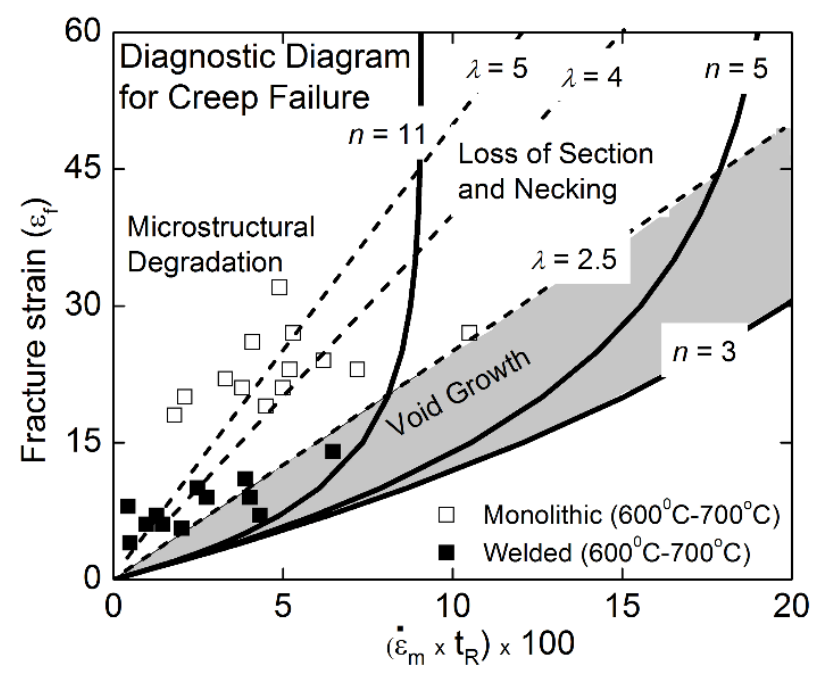

Fig. 13. A diagnostic diagram for creep failure for Grade 91 steel

The Larson-Miller parameter (LMP) was used for predicting creep rupture life of welded Grade 91 steel. LMP can be expressed in terms of rupture time and temperature as

$L M P=T\left(\log t_{R}+C\right)$,

where $T$ is the temperature $(\mathrm{K}), t_{R}$ the rupture time (hr), and $C$ the Larson-Miller constant, taken as 33 for this particular case. LMP values of Grade 91 steel decrease with increased stress, and the data obtained in the present study remain within the ambit of the databand obtained from other studies, as shown in Fig. 14. It should, however, be kept in mind that even though the Monkman-Grant relation and LMP can be used to predict rupture life, it does not provide the insights of the creep failure mechanisms. These approaches are empirically based, so their use may not lead to precise estimation of the creep rupture life and one should be aware of the danger associated with simple extrapolation. 


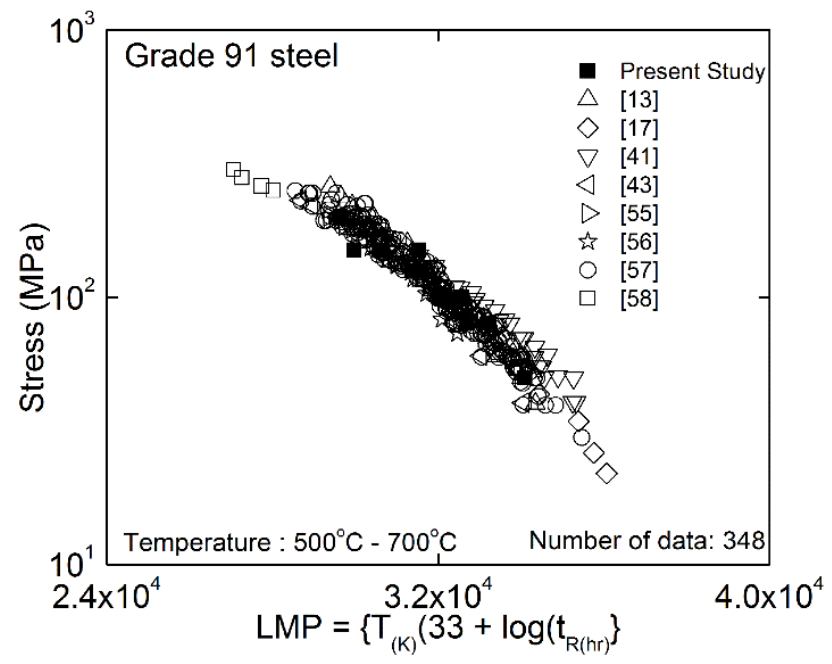

Fig. 14. Larson-Miller parameter plot of welded Grade 91 steels

\section{Conclusions}

The creep rupture behavior of welded Grade 91 steel was studied in the temperature range of $600{ }^{\circ} \mathrm{C}$ to $700{ }^{\circ} \mathrm{C}$ under applied stresses of $50-200 \mathrm{MPa}$, and compared with the creep rupture behavior of the monolithic (unwelded) Grade 91 steel. Mainly because of the formation of soft zones across the HAZ, the presence of heterogeneous microstructure, and other microstructural changes the welded Grade 91 steel had lower creep resistance than the monolithic form. The fractography of the creep ruptured specimens revealed transgranular failure with dimpled fracture surfaces. The creep rupture data were analyzed in terms of the Monkman-Grant relation, modified Monkman-Grant relation, and the Larson-Miller parameter. A diagnostic diagram for creep failure of Grade 91 steel was developed. The void growth accompanied by microstructural degradation in terms of substructure recovery was identified as the dominant creep failure mechanism in welded Grade 91. 


\section{Acknowledgment}

This research was performed using funding received from the DOE Office of Nuclear Energy's Nuclear Energy University Programs (NEUP) through the US Department of Energy grant no. 42246 release 59 .

\section{References}

[1] I. Charit, K.L. Murty, JOM 62 (9) (2010) 67-74.

[2] K.L. Murty, I. Charit, J. Nucl. Mater. 383 (2008) 189-195.

[3] D. Rojas, 9-12\% Cr heat resistant steels: alloy design, TEM characterization of microstructure evolution and creep response at $650^{\circ} \mathrm{C}$, Doctoral dissertation, Ruhr-University Bochum, Bochum, Germany, 2011.

[4] R. Vishwanathan, W.T. Bakker, Materials for boilers in ultra-supercritical power plants, ASME, Proceedings of 2000 International Joint Power Generation Conference, Miami Beach, Florida, July 23-26 (2000) 1-22.

[5] B.J.P. Buhre, R. Gupta, S. Richardson, A. Sharma, C. Spero; T. Wall, PF-Fired supercritical boilers: Operational issues and coal quality impacts. 2002 Report, CRC Coal Sustainable Development, University of Newcastle, 2/28/20.

[6] T. Shrestha, M. Basirat, I. Charit, G.P. Potirniche, K.K. Rink, Mater. Sci. Eng. A 565 (2013) 382-391.

[7] B.K. Choudhary and E.I. Samuel, J. Nucl. Mater. 412 (2011) 82-89.

[8] T. Shrestha, M. Basirat, I. Charit, G.P. Potirniche, K.K. Rink, J. Nucl. Mater. 423 (2012) 110-119.

[9] C.G. Panait, A. Zielinska-Lipiec, T. Koziel, A. Czyrska-Filemonowicz, A-F. Gourgues-Lorenzon, W. Bendick, Mater. Sci Eng. A 527 (2010) 4062-4069.

[10] K. Sawada, H. Kushima, M. Tabuchi, K. Kimura, Mater. Sci. Eng. A 528 (2011) 5511-5518.

[11] V. Sklenicka, K. Kucharova, M. Svoboda, L. Kloc, J. Bursik, A. Kroupa, Mater. Charact. 51 (2003) 35-48. 
[12] J. Hald, Int. J. Pres. Ves. Pip. 85 (2008) 30-37.

[13] K. Laha, K.S. Chandravathi, P. Parameswaran, K. Bhanu Sankara Rao, and S.L. Mannan, Metall. Mater. Trans. A 38 (2007) 58-68.

[14] P. Mayr, Evolution of microstructure and mechanical properties of the heat affected zone in B-containing 9\% chromium steels, Doctoral dissertation, Graz University of Technology, Austria, 2007.

[15] S. Spigarelli and E. Quadrini, Mater. Des. 23 (2002) 547-552.

[16] S.K. Albert, M. Matsui, T. Wanatabe, H. Hongo, K. Kubo, M. Tabuchi, Int. J. Pres. Ves. Pip. 80 (2003) 405-413.

[17] M. Yaguchi, T. Ogata, T. Sakai, Int. J. Pres. Ves. Pip. 87 (2010) 357-364.

[18] J. Parker, Int. J Pres. Ves. Pip. 114-115 (2014) 76-87.

[19] Y. Li, Y. Monma, H. Hongo, M. Tabuchi, J. Nucl. Mater. 4005 (2010) 44-49.

[20] M.L. Santella, S.S. Babu, R.W. Swindeman, E.D. Specht, In-situ characterization of austenite to martensite decomposition in $9 \mathrm{Cr}-1 \mathrm{Mo}-\mathrm{V}$ steel welds, Proc. Austenite Formation \& Decomposition Symposium, TMS, Nov. 09-12, 2003, Chicago, IL USA.

[21] V.T. Paul, S. Saroja, P. Hariharan, A. Rajadurai, and M. Vijayalakshmi, J. Mater. Sci. 42 (2007) 5400-5713.

[22] S.J. Sanderson, In: A.K. Khare (ed.), Proceedings of conference on ferritic steels for high-temperature applications. Warrendale, PA, 1981. ASM Metals Park, p. 85.

[23] M. Vijayalakshmi, S. Saroja, V.T. Paul, R. Mythili, V.S. Raghunathan, Metall. Trans. 30A (1999) pp. 161.

[24] R. Kishore, R.N. Singh, T.K., Sinha B.P. Kashyap, J. Nucl. Mater. 195 (1992) pp. 198

[25] O. Grong, In: Metallurgical modelling of welding, 2nd ed. (1997), The Institute Of Materials, London, UK, pp. 28.

[26] Y. You, R. Shiue, J. Mater. Sci. Lett. 20 (2001) 1429-1432.

[27] B. Arivazhagan, R. Prabhu, S. K. Albert, M. Kamaraj, S. Sundaresen, J. Mater. Eng. Perf. 18(8) (2009) 999-1004. 
[28] M. Basirat, T. Shrestha, G.P. Potirniche, I. Charit, K. Rink, Int. J. Plast. 37 (2012) 95-107.

[29] T. Shrestha, S.F. Alsagabi, I. Charit, G. P. Potirniche, M.V. Glazoff, Metals, 5 (2015) pp. 131-149.

[30] M. Turski, A.H. Sherry, P.J. Bouchard, P.J. Withers, J. Neutron Res. 12(1-3) (2004) 45-49.

[31] P.J. Bouchard, P.J. Withers, S.A. McDonald, R.K. Heenan, Acta Mater. 52(1) (2004) 23-34.

[32] T. Shrestha, I.Charit, G. Potirniche, J. Mater. Eng. Perf. 24(1) (2015 4710-4720.

[33] S.K. Albert, M. Matsui, H. Hongo, T. Watanabe, K. Kubo, M. Tabuchi, Int. J. Press. Vess. Pip. 81 (2004) 221-234.

[34] D. Li, K. Shinozaki, Sci. Technol. Weld. Join. 10(5) (2005) 544-549.

[35] T. Watanabe, M. Yamazaki, H. Hongo, M. Tabuchi, T. Tanabe, Int. J. Press. Vess. Pip. 81 (2004) 279-284.

[36] A.R. Pyzalla, Internal stresses in engineering materials, in: W. Reimers, A.R. Pyazalla, A. Schreyer, H. Clemens (Eds.), Neutrons and Synchrotron Radiation in Engineering Materials Science, Wiley-VCH, Weinheim, 2008, pp. 21-56.

[37] H. Dai, J.A. Francis, H.J. Stone, H.K.D.H Bhadeshia, P.J. Withers, Met. Mater. Trans. A 39 (2008) 3070-3078.

[38] E. Barker, Mater. Sci. Eng. 84 (1986) 49-64.

[39] S.A. David, T.Debroy, Sci. 257 (1992) 497-502.

[40] M. Regev, S. Berger, B.Z. Weiss, Weld. J. 75 (1996) 261s-268s.

[41] T. Sato, K. Tamura, Advances in Materials Technology for Fossil Power Plants: Proceedings of the $5^{\text {th }}$ International Conference, Oct. 3-5, 2007, Marco Island, FL, USA, ASM Int., 2008, 874-883.

[42] G.E. Dieter, Mechanical Metallurgy, 3rd ed., McGraw-Hill, Boston, MA, 1986.

[43] M. Yamazaki, T. Watanabe, H. Hongo, M. Tabuchi, J. Pow. Eng. Sys. 2(4) (2008) 1140-1149.

[44] A.C.F. Cocks, M.F. Ashby, Prog. Mater. Sci. 27 (1982) 189-244. 
[45] H. Riedel, Fracture at High Temperatures, Springer-Verlag Berlin, Heidelberg, Germany, 1987, 215-24.

[46] F.C. Monkman, N.J. Grant, Proc. ASTM 56 (1956) 593-620.

[47] F.R.N. Nabarro, H.L. de Villiers, The Physics of Creep, Taylor \& Francis, London, 1995, pp. 22-25.

[48] H. E. Evans: Mechanics of Creep Fracture, Elsevier Applied Science Publishers, New York, NY, 1984, 18-22.

[49] L. Falat, A. Vyrostkova, V. Homolova, and M. Svoboda, Eng. Fail. Anal. 16 (2009) 2114-2120

[50] F. Dobes, K. Milicka, Metal Sci. 10 (1976) 382-384.

[51] F.A. Leckie, D.R. Hayhurst, Acta Metall. 25 (1977) 1059-1070.

[52] M.F. Ashby, B.F. Dyson: in Advances in Fracture Research, Eds. S.R. Valluri et al. Vol. 1, Pergamon Press, Oxford, 1984, 3-30.

[53] B.K. Choudhary, C. Phaniraj, B. Raj, Trans. Ind. Inst. Met. 63 (2010) 675-680.

[54] B. Wilshire, H. Burt, Z. Metallkd. 96 (2005) 552-557.

[55] F. Masuyama, Int. J. Pres. Ves. Pip. 83 (2006) 819-825.

[56] S.J. Brett, D.J. Allen, L.W. Buchanan, The type IV creep strength of Grade 91 materials. In: Proceedings of the third international conference on integrity of high temperature welds. Institute of Materials; 2007, 409-20.

[57] M. Tabuchi, Y. Takahashi, J. Pres. Ves. Technol. 134 (2012) 031401-6.

[58] F. Vivier, J. Besson, A.F. Gourgues, Y. Lejeail, Y. de Carlan, S. Dubiez, in: Creep behavior and life prediction of ASME Gr. 91 steel welded joints for nuclear power plants, eds. Le Goff et al., Mines-Paris Tech, France, 2008, pp. 1-2. 